
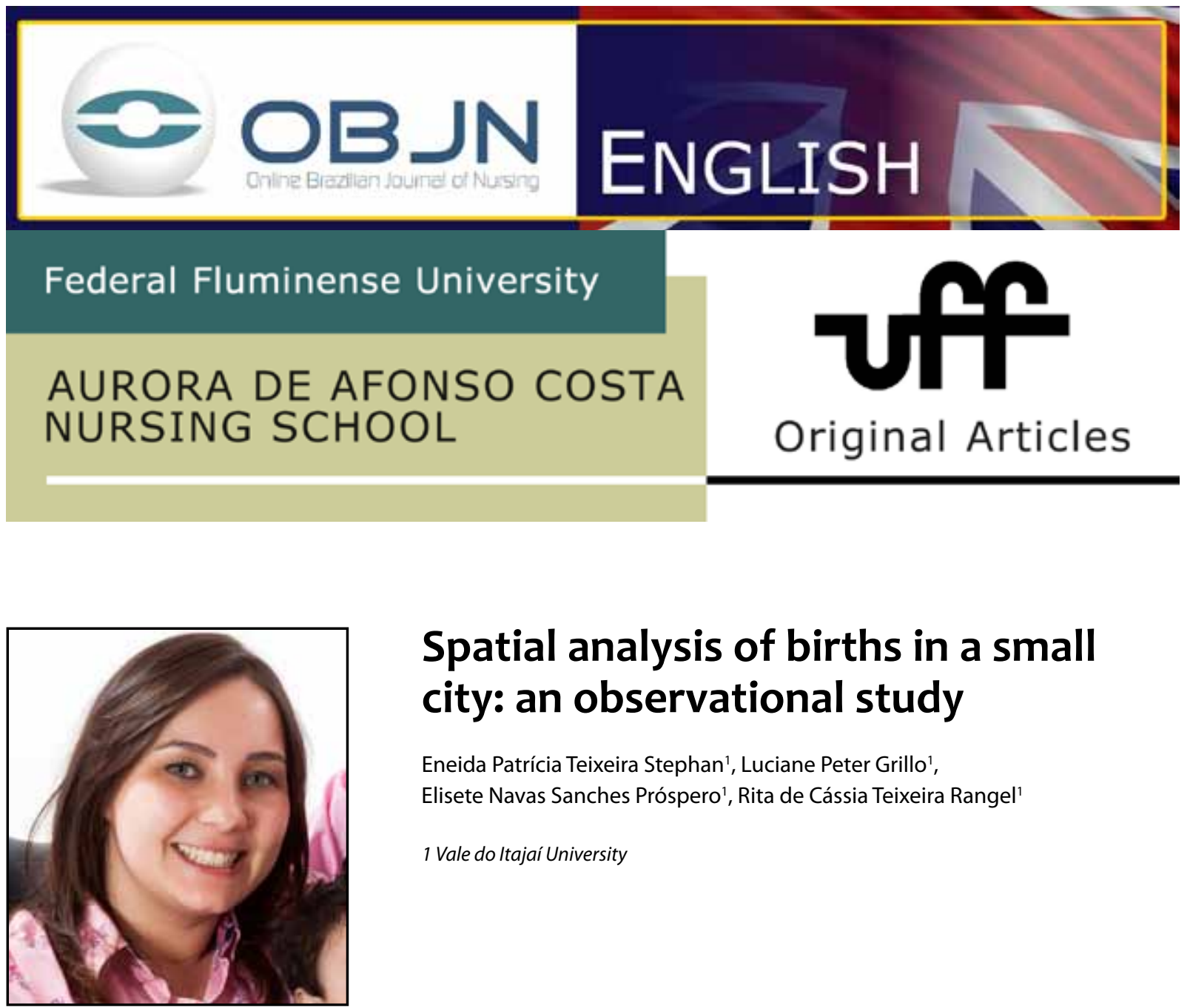

\title{
Spatial analysis of births in a small city: an observational study
}

Eneida Patrícia Teixeira Stephan', Luciane Peter Grillo',

Elisete Navas Sanches Próspero', Rita de Cássia Teixeira Rangel ${ }^{1}$

1 Vale do Itajaí University

\begin{abstract}
Aim: To evaluate the conditions of birth of infants born to mothers residing in the city of Balneario Piçarras, SC. Method: Ecological exploratory study using a quantitative analysis. The database used was the Live Birth Information System. The population was composed of the set of live births recorded from 2008 to 2011. Results: Births are characterized by newborns of mothers aged 20 to 34 years old, single, with eight or more years of education, and prenatal monitoring of seven or more visits; there was a predominance of vaginal delivery, at term, of male newborns, with proper weight. The spatial analysis of indicators shows that the risks are associated with poor access to health services in rural towns and the unfavorable socioeconomic conditions in the urban area.
\end{abstract}

Descriptors: Birth Weight; Birth Certificates; Spatial Analysis. 


\section{INTRODUCTION}

Health services highlight low birth weight (weight less than $2500 \mathrm{~g}$ ) and prematurity as main action focuses, allocating to them special care practices and monitoring, due to problems such as high morbidity and mortality, and an increased risk of retardation in growth and development in these cases, which constitute groups vulnerable to the impact of environmental and social conditions ${ }^{(1)}$. Birth weight, a factor present in studies since the 1950s, stands out among the health indicators. The World Health Organization (WHO) recognizes it as the most important element associated with the chance of survival, growth and normal development of newborns, and one of the indicators used to determine the health and nutritional status of the population, reflecting its quality of life. Reaching normal intrauterine growth potential is critical since a deficit in growth is the main risk factor in the increase in infant mortality rates, due to the child's subsequent vulnerability in the first months of life ${ }^{(2)}$.

The duration of pregnancy is important for intrauterine growth and has a further impact on the newborn's [chances of] survival. A reduction in pregnancy time will lead to a preterm birth and the risk of immaturity of organs - a concern for perinatology, given the high neonatal mortality rates linked to prematurity. It is estimated that $75 \%$ of neonatal deaths involve preterm deliveries, or complications from these to the newborns ${ }^{(2,3)}$.

The Live Birth Information System (SINASC) has been used to describe populations of live births in Brazilian municipalities and regions, with a national coverage rate of $92 \%{ }^{(4)}$. It is a national information system managed by the Health Situation Analysis Department of the Health Surveillance Secretariat, together with state and municipal departments. Implemented in all federal units since 1990, it gathers epidemiological information on births in the country. The Birth Certificate (DNV) is its data collection instrument, a personal and standardized document with about 30 variables ${ }^{(5,6)}$.

In this sense, georeferencing is a tool for analysis and evaluation of risks to public health related to the environment and socio-economic profile of the population. These data analysis technologies are being used more and more, bringing new information for planning and evaluating actions based on analysis of the spatial distribution of diseases and location of services and environmental risks, and other aspects of the territory and population ${ }^{(6,7)}$.

This study is the result of a partnership between the Department of Health of Balneário Piçarras (SC) and the Occupational Management and Health Master's Degree Program of the University of Vale do Itajaí, which is an important relationship between academic work and public health services. The goal is to evaluate the birth conditions of children born to mothers residing in the city between 2008 and 2011, from the analysis of SINASC data, through the following indicators: low weight at birth, overweight at birth and prematurity.

\section{METHODS}

This is an ecological analysis of a quantitative exploratory study in Balneario Picarras, Foz do Vale di Itajaí, on the north coast of Santa Catarina: a city with 17,552 inhabitants, a female population of $8795-4641$ of which are of childbearing age (15-49 years) - and 280 children under one year of age ( 136 male and 144 female).

Geographically, the city is divided into six neighborhoods in the urban area (Downtown, Itacolomi, Santo Antonio, Bela Vista, Nossa Senhora da Conceição and Nossa Senhora da Paz) 
and seven locations in the countryside (Morro Alto, Morretes, Lagoa, Medeirinhos, Nova Descoberta, São Braz and Rio Novo). It falls within the $75 \%$ of Brazilian municipalities with less than 25,000 inhabitants. Due to its small size, it has had no [previous] socioeconomic evaluation as part of demographic censuses by the Brazilian Institute of Geography and Statistics (IBGE). We used indirect indicators - housing and sanitation data - to assess the social and health conditions, according to the study by Monteiro and Nazario $^{(8)}$. These data are from the Primary Care Information System. $100 \%$ of the city has Family Health Strategy (FHS) coverage.

In the urban areas, Downtown and Santo Antonio are the oldest neighborhoods in the city, composed of old and traditional families. The Nossa Senhora da Conceição neighborhood was expanded in the 1970s with migrants from Minas Gerais and Paraná. They have a water supply (public, 92\%); garbage collection (public collection, 99\%); sewage (sewage system, 29\%; Septic tank, $69 \%) ;$ and most of residences are constructed from masonry (69\%). The population is served by three Basic Health Units (BHU): Downtown, Santo Antonio and Nossa Senhora da Conceição.

An important fact about Nossa Senhora da Paz, Bela Vista and Itacolomi neighborhoods is the number of migrants from western Santa Catarina and Paraná, accounting for all the slum inhabitants. Despite this and the fact that they are located near the center of the city, they present a high population density and are equipped with a water supply (public, 97.29\%); garbage collection (public, 99.30\%); and sewage (system, 57.67\%; Septic, 40.85\%; ditch, 1.47\%). Their houses are made of brick (71.5\%) and wood (27.5\%). The population is served by two BHUs: Nossa Senhora da Paz (two teams) and Bela Vista (Bela Vista and Itacolomi).

In the rural areas, the population is descended from Italians and Germans, and composed mainly of farmers dedicated to banana and rice plantations and subject to environmental risks from inadequate cultivation processes (indiscriminate pesticides). With a low population density, they lack infrastructure, with access to the: water supply (public system, 3.04\%; well or spring, 96.96\%); garbage collection (public, 46.01\%; burnt/buried, $49.05 \%$ ); and sewage (system, $1.52 \%$; Septic, $83.65 \%$; ditch, $14.83 \%$ ). $41.44 \%$ of their houses are masonry, while $57.59 \%$ are wood and mixed materials. The population is served by one BHU - Morro Alto (Morretes, Medeirinhos, São Braz, Nova Descoberta and Rio Novo). Lagoa neighborhood receives assistance from the Nossa Senhora da Conceição BHU, due to its geographic location.

The study population consisted of 983 birth certificates from Balneario Piçarras, for births between 2008-2011, a period requested by the Municipal Health Management to assess the indicators. Data were gathered from the Municipal Health Department, from the database and SINASC reports provided by Regional Health Management, in October 2012. The city does not feed the SINASC database since there are no maternity hospitals present in its territory, but it provides feedback about the birth certificates of mothers living in the city.

The data were formatted within Excel spreadsheets; 10 cases were excluded due to the address information being missing or not corresponding to the municipality. Therefore, 973 birth certificates in total were included.

\section{Variables Used}

The variables used were: 1) Newborn's birth weight - in grams. Categories: Low weight (values between 1,500g and 2,499g); Insufficient weight (between 2,500g and 2,999g); Suita- 
ble weight (between 3,000g and 3,999g); and Overweight (values $\geq 4,000 \mathrm{~g}$ ).

2) Gestational age - duration of pregnancy in weeks, at delivery. Categories: Pre-term ( $\leq 36$ weeks of gestation); At term (37-41 weeks); and Post-term ( $\geq 42$ weeks).

3) Geographic - corresponds to the mother's place of residence.

Underweight and overweight prevalence at birth and prematurity for each local municipality were calculated according to the following formula:

Prevalence $=$ number of low weight, overweight and pre-term births in B. Piçarras, 2008-2011 x100

Number of births in B. Piçarras 2008-2011

The thematic maps considered the percentiles (thirty-third and sixty-sixth) of each of the indicators. Values lower than the thirty-third percentile were considered as low risk (green), intermediate values, as moderate risk (yellow) and the ones above the sixty-sixth percentile as high risk (red). A map standard was applied to all maps. The results of the statistical analyses, including the percentiles calculated, were associated with the base vector and each zone received a corresponding amount. These values, referred to as "attributes of vectors", allow for the representation of the data in association with colors, overlay graphics, density points, etc.

For the development of georeferencing of intra-urban differentials, the city of Balneario Picarras was used as the unit of analysis. The spatial analysis involved the preparation of a cartographic base at a 1:50,000 scale in the Geographic Information System (GIS), with municipal division (IBGE Topographical Letters); the ArcGis 9.3 was the GIS platform adopted. This allowed us to map the prevalen- ce of weight and gestational age associated with 13 districts and neighborhoods of Balneario Picarras. We also managed to prepare the cartographic base with IBGE census data, to input and correlate the birth weight and gestational age data with geoinformation within spreadsheets, and to elaborate the thematic maps of the indicators.

The project was approved by the Ethics in Research Committee of UNIVALI under Protocol 115220 of $28 / 09 / 12$.

\section{RESULTS}

Most births in Balneario Picarras occurred in the urban area (90.44\%). Only $9.55 \%$ occurred in the countryside.

The data in Table 1 refer to the 973 birth certificates registered in the SINASC database from 2008 to 2011, for the following variables: maternal (maternal age, marital status, education), assistance (number of prenatal visits, type of delivery) and newborn (gestational age of the newborn, gender, birth weight).

We observed that the average age of the mothers was 25.82 years \pm 6.54 years, with the highest concentration in the age group 20-34 years old (68.13\%), single (56.83\%) and with a predominant education level of eight years of study (69.06\%). As for the variables of assistance to prenatal care and childbirth, there was evidence of good prenatal coverage (seven or more visits, 81.80\%). As for delivery, there was a higher prevalence of vaginal deliveries (53.64\%). Regarding newborn variables, 93.01\% were born with term gestational age, the appropriate period for births, and were predominantly male $(51.90 \%)$. As for birth weight, $65.5 \%$ were normal weight, $6.1 \%$ were underweight, and $7.2 \%$ overweight. 
Table 1 - Population distribution according to maternal and newborn characteristics in period 2008 - 2011, Balneario Piçarras, 2012.

\begin{tabular}{|c|c|c|c|c|c|}
\hline Variables & $\mathbf{N}$ & $\%$ & $\begin{array}{l}\text { Avera- } \\
\text { ge }\end{array}$ & $\begin{array}{c}\text { Std. } \\
\text { Devia- } \\
\text { tion }\end{array}$ & $\begin{array}{l}\text { Me- } \\
\text { dian }\end{array}$ \\
\hline \multicolumn{6}{|l|}{ Maternal } \\
\hline - Maternal Age: & & & 25,82 & 6,54 & 25 \\
\hline$\leq 19$ years old & 196 & 20,14 & & & \\
\hline 20-34 years old & 663 & 68,13 & & & \\
\hline$>35$ years old & 114 & 11,71 & & & \\
\hline \multicolumn{6}{|l|}{ - Marital status: } \\
\hline Single & 553 & 56,83 & & & \\
\hline Married & 379 & 38,95 & & & \\
\hline Widow & 5 & 0,51 & & & \\
\hline Divorced & 14 & 1,43 & & & \\
\hline $\begin{array}{l}\text { Common law } \\
\text { union }\end{array}$ & 22 & 2,26 & & & \\
\hline \multicolumn{6}{|l|}{ - Education: } \\
\hline None & 2 & 0,2 & & & \\
\hline $1-3$ years & 25 & 2,56 & & & \\
\hline 4-7 years & 272 & 27,95 & & & \\
\hline $8-11$ years & 502 & 51,59 & & & \\
\hline$>12$ years & 170 & 17,47 & & & \\
\hline Unknown & 2 & 0,2 & & & \\
\hline \multicolumn{6}{|c|}{ Assistance- Number of prenatal visits: } \\
\hline None & 9 & 0,92 & & & \\
\hline $1-3$ visits & 27 & 2,77 & & & \\
\hline $4-6$ visits & 138 & 14,18 & & & \\
\hline 7 or more visits & 796 & 81,8 & & & \\
\hline Unknown & 3 & 0,3 & & & \\
\hline \multicolumn{6}{|l|}{ - Delivery: } \\
\hline Vaginal & 522 & 53,64 & & & \\
\hline Caesarean & 451 & 46,35 & & & \\
\hline \multicolumn{6}{|c|}{ Newborn - Gestational age: } \\
\hline Preterm & 61 & 6,26 & & & \\
\hline At term & 905 & 93,01 & & & \\
\hline Post-term & 7 & 0,71 & & & \\
\hline \multicolumn{6}{|c|}{ - Newborn gender: } \\
\hline Female & 468 & 48,09 & & & \\
\hline Male & 505 & 51,9 & & & \\
\hline - Birth weight: & & & 3271,02 & 541,13 & 3300 \\
\hline $\begin{array}{l}\text { Very Low } \\
\text { weight }\end{array}$ & 8 & 0,82 & & & \\
\hline Low weight & 59 & 6,1 & & & \\
\hline $\begin{array}{l}\text { Insufficient } \\
\text { weight }\end{array}$ & 199 & 20,5 & & & \\
\hline $\begin{array}{l}\text { Appropriate } \\
\text { Weight }\end{array}$ & 637 & 65,5 & & & \\
\hline Overweight & 70 & 7,2 & & & \\
\hline
\end{tabular}

Source: Live Birth Information System (SINASC), Health

Department of Balneario Picarras, 2012.
In Table 2, we can observe the birth data sorted by neighborhoods, according to the prevalent birth weight and gestational age: low weight (BP), underweight (PI), normal weight (PA), overweight (SP), pre-term, term and post-term. We observed that the highest prevalence of low birth weight, with values above the prevalence of the municipality $(6.10 \%)$, occurred in the town of São Braz (13.3\%). In relation to underweight newborns, the prevalence was highest in the Lagoa location (28.57\%). Regarding the normal birth weight, the neighborhood with highest rates was Nova Descoberta (87.50\%). As for the prevalence of overweight newborns (7.20\%), the fact that this was higher than the prevalence of low birth weight $(6.10 \%)$ was called to our attention. The neighborhood with the highest prevalence of overweight was Medeirinhos (33.33\%). As for the gestational age, the highest prevalence of each category were: preterm births - São Braz (13.33\%); term births - Lagoa, Morro Alto and Nova Descoberta (100.00\%); and post-term births - Medeirinhos (11.11\%).

From Figure 1, we can confirm that St. Braz, Bela Vista and Nossa Senhora da Paz are the highest risk locations for low birth weight, with prevalence ranging from 8.80 to $13.30 \%$, in red. However, all the districts of the urban area and neighboring districts of rural areas had an average risk ranging from 0.00001 to $8.80 \%$, in yellow.

In Figure 2, we can observe that the greatest risk for overweight births was in the Medeirinhos neighborhood, with a range of prevalence rates between $14.20 \%$ and $33.40 \%$, in red.

In Figure 3, you can see that São Braz is the place with the highest risk of preterm births, with prevalence rates ranging between $8.90 \%$ and $13.40 \%$, in red. 
Table 2 - Distribution of prevalences of Birth Weight and Gestational Age by neighborhoods in the period 2008 - 2011, Balneario Piçarras, 2012.

\begin{tabular}{|c|c|c|c|c|c|c|c|}
\hline \multirow{2}{*}{ Neighboorhood } & \multicolumn{4}{|c|}{ Birth Weight } & \multicolumn{3}{|c|}{ Gestational Age } \\
\hline & BP & PI & PA & SP & Preterm & At term & Post term \\
\hline \multirow{2}{*}{ Balneário Piçarras } & 59 & 199 & 637 & 70 & 60 & 906 & 7 \\
\hline & 6,1 & 20,5 & 65,5 & 7,2 & 6,16 & 93,11 & 0,71 \\
\hline \multirow{2}{*}{ Bela Vista } & 4 & 8 & 30 & 3 & 1 & 45 & 0 \\
\hline & 8,69 & 17,39 & 65,21 & 6,52 & 2,17 & 97,82 & 0 \\
\hline \multirow{2}{*}{ Centro } & 10 & 50 & 139 & 12 & 14 & 196 & 3 \\
\hline & 4,69 & 23,47 & 65,25 & 5,63 & 6,57 & 92,01 & 1,4 \\
\hline \multirow{2}{*}{ Itacolomi } & 6 & 20 & 66 & 12 & 7 & 96 & 2 \\
\hline & 5,71 & 19,04 & 62,85 & 11,42 & 6,66 & 91,42 & 1,9 \\
\hline \multirow{2}{*}{ Lagoa } & 0 & 6 & 12 & 3 & 0 & 21 & 0 \\
\hline & 0 & 28,57 & 57,14 & 14,28 & 0 & 100 & 0 \\
\hline \multirow{2}{*}{ Medeirinhos } & 0 & 0 & 6 & 3 & 0 & 8 & 1 \\
\hline & 0 & 0 & 66,66 & 33,33 & 0 & 88,88 & 11,11 \\
\hline \multirow{2}{*}{ Morretes } & 2 & 5 & 19 & 1 & 1 & 26 & 0 \\
\hline & 7,4 & 18,51 & 70,37 & 3,7 & 3,7 & 96,29 & 0 \\
\hline \multirow{2}{*}{ Morro Alto } & 0 & 2 & 6 & 0 & 0 & 8 & 0 \\
\hline & 0 & 25 & 75 & 0 & 0 & 100 & 0 \\
\hline \multirow{2}{*}{ Nossa Senhora da Conceição } & 3 & 12 & 53 & 6 & 2 & 73 & 0 \\
\hline & 4,05 & 16 & 70,62 & 8 & 2,66 & 97,33 & 0 \\
\hline \multirow{2}{*}{ Nossa Senhora da Paz } & 24 & 57 & 183 & 23 & 25 & 265 & 0 \\
\hline & 8,27 & 19,65 & 63,1 & 7,93 & 8,62 & 91,37 & 0 \\
\hline \multirow{2}{*}{ Nova Descoberta } & 0 & 1 & 7 & 0 & 0 & 8 & 0 \\
\hline & 0 & 12,5 & 87,5 & 0 & 0 & 100 & 0 \\
\hline \multirow{2}{*}{ Rio Novo } & 0 & 1 & 4 & 0 & 0 & 5 & 0 \\
\hline & 0 & 20 & 80 & 0 & 0 & 100 & 0 \\
\hline \multirow{2}{*}{ Santo Antônio } & 8 & 34 & 102 & 7 & 8 & 142 & 1 \\
\hline & 5,29 & 22,51 & 67,54 & 4,63 & 5,29 & 94,03 & 0,66 \\
\hline \multirow{2}{*}{ São Braz } & 2 & 3 & 10 & 0 & 2 & 13 & 0 \\
\hline & 13,33 & 20 & 66,66 & 0 & 13,33 & 86,66 & 0 \\
\hline
\end{tabular}

Source: Live Birth Information System (SINASC), Health Department of Balneario Picarras, 2012.

\section{DISCUSSION}

The results of this study allow for an analysis of births in Balneario Picarras in the period 20082011, a small municipality with characteristics comparable with to many municipalities in Brazil with regard to infrastructure and provision of resources for the health sector.

Regarding maternal age, the findings are similar to other studies, indicating a concentration in the age group 20-34 years (68.13\%) and a relatively high rate for adolescent mothers (20.14\%). A study in Goiânia, $\mathrm{GO}^{(9)}$, presented $68.55 \%$ and $25.86 \%$, respectively. In Foz do
Iguaçu, $\mathrm{PR}^{(10)}$, variations from 66.97 to $71.38 \%$ were registered for that age group, with births to adolescents ranging from 19.21 to $24.55 \%$, and an even higher rate of teenage mothers in Guarapuava, PR (34\%) ${ }^{(3)}$.

An analysis conducted in maternity hospitals in Aracaju, SE, revealed that teenage mothers experienced lower socioeconomic and reproductive conditions, and more adverse perinatal outcomes, compared to other age groups. The proportion of low birth weight and prematurity was twice as high among adolescents younger than 18 years than among mothers of other age groups. The authors note that teenage pregnancy is also associated with adverse pregnancy 


\section{Figure 1}

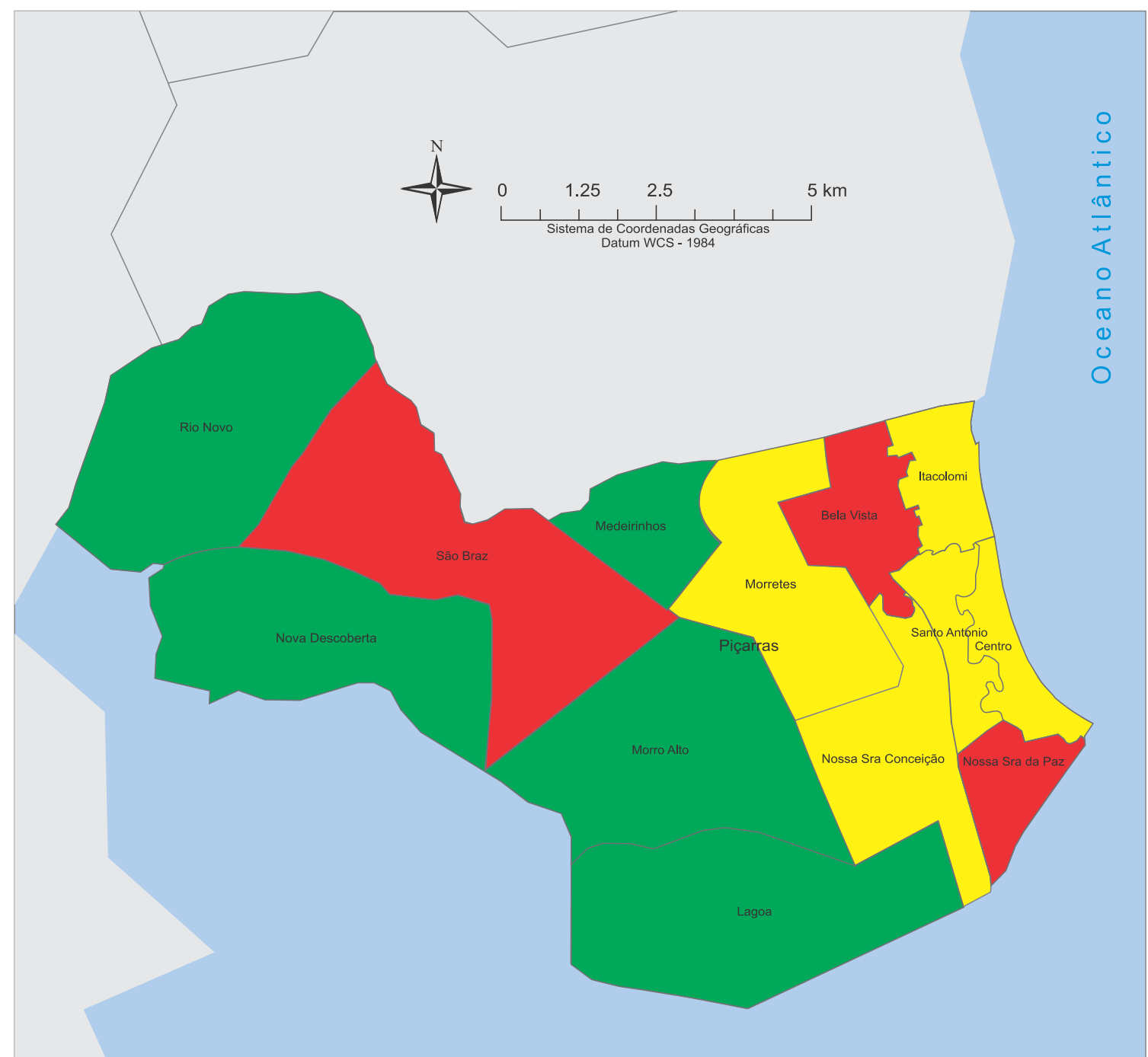

\section{Distribution of prevalence rate of low birth weight in the}

neighborhoods of the city of Balneario Picarras-SC between 20082011

Prevalence of low birth weight

Number of births in the period used to calculate the coefficient:

973

Map compiled from data provided by SINASC

Balneário Piçarras-SC

In charge of mapping: Angelina Coelho
0.00

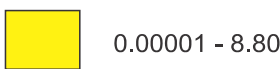

$8.800001-13.35$ 


\section{Figure 2}

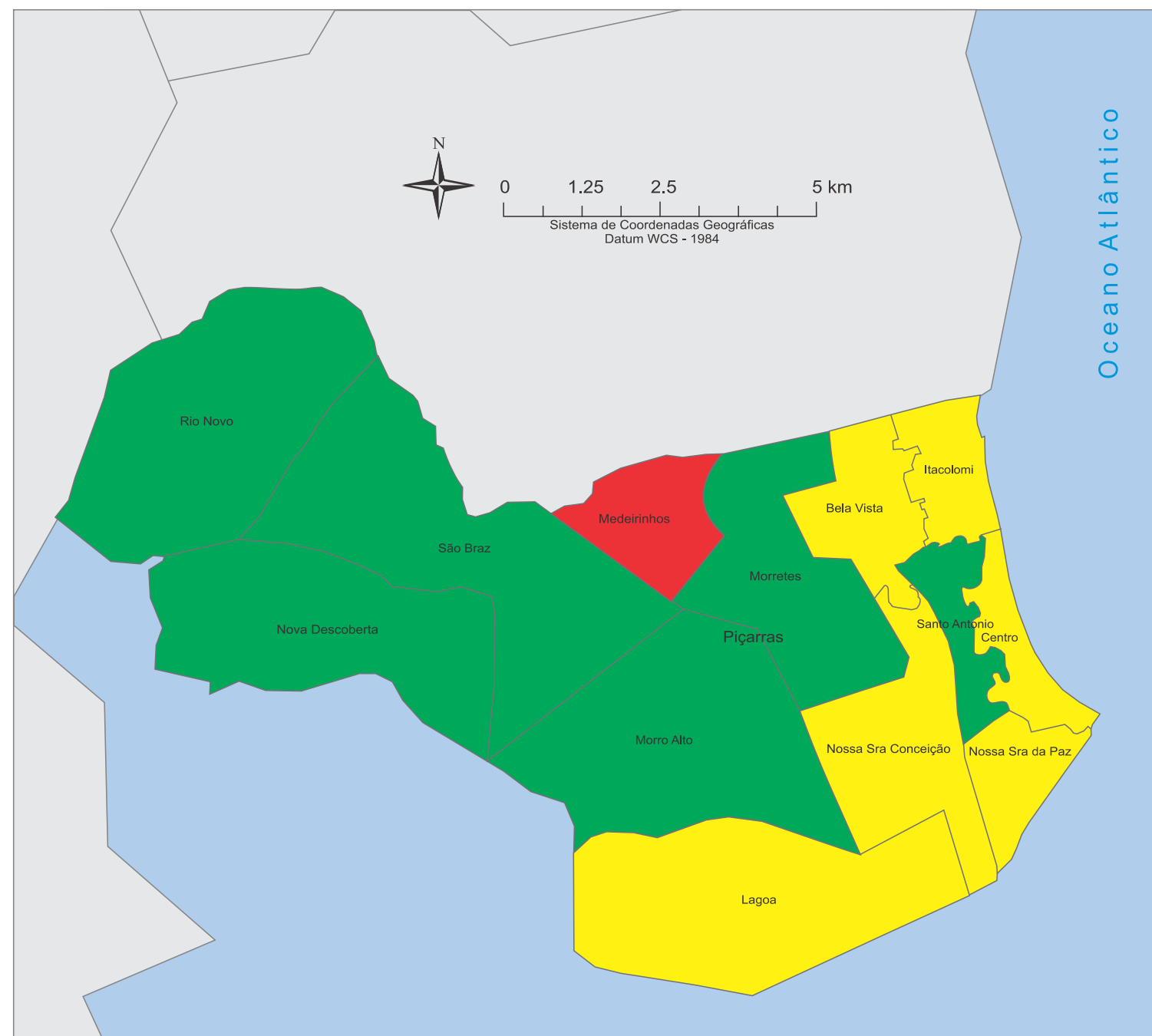

Distribution of prevalence rate of overweight in the neighborhoods of the city of Balneario Picarras-SC between 2008-2011

Prevalence of overweight birth

Number of births in the period used to calculate the coefficient:

973

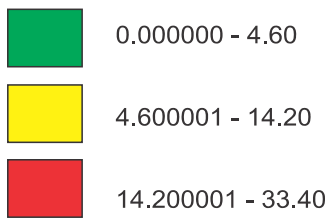

In charge of mapping: Angelina Coelho 


\section{Figure 3}

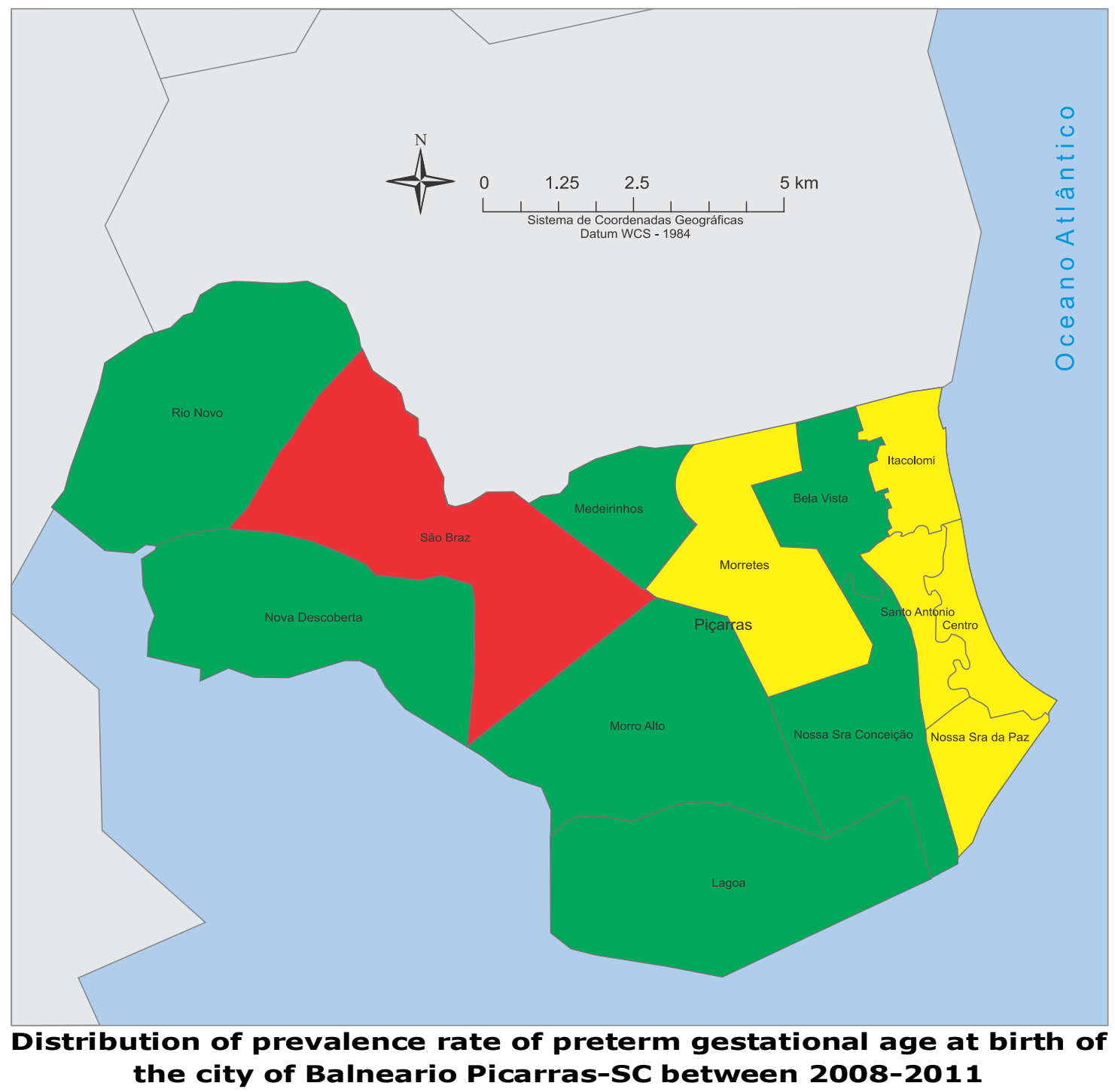

Prevalence rate of preterm gestational age at birth

Number of births in the period used to calculate the coefficient:

973

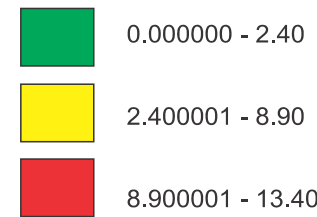

Map compiled from data provided by SINASC

Balneário Piçarras-SC

In charge of mapping: Angelina Coelho 
outcomes due to social vulnerability, since only adolescents without partners were observed ${ }^{(11)}$.

The percentage of mothers older than 35 years $(11.71 \%)$ is also noteworthy, as it is a higher rate than that found in another study $-4.62 \%$ (Goiânia, GO) $)^{(9)}$ - yet similar to studies of Niterói, RJ: $11.8 \%(2000)$ to $14.3 \%(2009)^{5}$.

As to prenatal coverage, of seven or more visits $(81.80 \%)$, the findings were higher than those found in other studies: a range from 26.60 to $66.46 \%$ in Foz do Iguaçu, PR ${ }^{(10)} ; 53.28 \%$ in Goiânia, GO ${ }^{(9)}$; and 70\% in Vale do Paraíba ${ }^{(6)}$. According to the National Demographic and Health Survey, PNDS $2006^{(13)}$, the Southeast, South and Midwest showed the best situation regarding prenatal care, with percentages of $88.2,87.5$ and $83.7 \%$, respectively.

The high cesarean delivery rate found (46.35\%) has also been identified in other studies: $56.3 \%$ in Vale do Paraíba, SP(6); and a variation from 33.84 to $49.94 \%$ in Foz do Iguaçu, $\mathrm{PR}^{(10)}$. Although there is evidence of association between cesarean deliveries and maternal morbidity and mortality, no signs of reduction in the current trend of increase in these surgeries were detected ${ }^{(4)}$.

The monitoring of birth weight is critical for two reasons: first, because it is intrinsically related to the health and nutrition of pregnant women, the length of gestation and fetal growth. Second, it represents the single most important factor to evaluate the survival, growth and development of the child. A reduction in the incidence of newborns with a low birth weight would be one of the indicators of progress of a country or region; therefore, such a reduction is expected to be reflected in the decrease of infant morbidity and mortality, and will have economic, political and health repercussions ${ }^{(2)}$.

In the city of Balneario Piçarras, the prevalence values of low weight at birth (6.10\%) have a similar distribution to low birth weight rate found in Brazil as a whole (6.1\%), in the state capital, Florianópolis (6.68\%), and in the region of Foz do Rio Itajaí Açu (6.29\%). It is lower than the rates for the South (8.71\%) and for Santa Catarina $(7.99 \%)^{(12)}$.

It is noteworthy that the prevalence of overweight (7.20\%) was higher than that of low birth weight (6.10\%), higher than that found in the region of Foz do Rio Itajai Açu (5.87\%) and in Florianópolis (5.91\%) $)^{(12)}$.

A study to investigate the social, demographic, biological and environmental determinant factors for low birth weight in Brazil, which used data from PNDS 2006, found a prevalence of low weight of $6.1 \%$ (a reduction in relation to PNDS 1996, which reported a prevalence of $8.1 \%$ ). Risk factors were identified for low birth weight with odds ratios ranging from 1.55 to 2.22 , as follows: female, living in the Southeast and South regions, maternal education of less than four years, and smoking habits. Studies using surveys such as PNDS have more comprehensive information for analytical approaches to low weight at birth data, which are not available in the SINASC database ${ }^{(13)}$.

In the study mentioned above, a higher prevalence of low birth weight was observed among families of higher socioeconomic status, reinforcing the idea that an increase in low birth weight is related to prematurity and access to the health technologies available in the more developed regions, resulting in lower infant mortality rates. This phenomenon is called the epidemiological paradox of low birth weight ${ }^{(13)}$.

Some authors suggest that Brazil is experiencing a perinatal epidemiological transition, in which increased low birth weight is identified in more developed regions, supported by advanced technologies in neonatal medicine. A reduction in pregnancy time due to the increased number of elective cesarean deliveries, either by the mother's and/or obstetrician's choice, can also be identified ${ }^{(14)}$. 
The spatial distribution of low birth weight in Balneario Piçarras revealed that São Braz, Bela Vista and Nossa Senhora da Paz are locations with a higher of low birth weight. Nossa Senhora da Paz and Bela Vista are the neighborhoods with the highest concentration of socioeconomic poverty, a context that reinforces the need for special attention to maternal and child monitoring, with a guarantee of access to prenatal care and continuity of care at all levels of attention available at the municipal health network. The district of São Braz, as it is situated in the countryside, presented difficulties regarding access to health services, which is an increased risk factor for pregnant women and their babies, especially when considering weight as an indicator of health ${ }^{(15)}$. In addition, all the other districts of the urban area had an average risk for low birth weight, reinforcing the idea that, in the urban areas where most of the population is concentrated, and especially the two extremes of the social strata, low birth weight should be monitored and used as an indicator for the evaluation of care quality provided by health services, as well as the indiscriminate use of delivery technologies.

The spatial analysis used in studies for the planning and management of health services is a great facilitator for understanding these phenomena, making use of the knowledge of strategies to improve health care. Low birth weight is a determinant factor of neonatal mortality, associated with infections and longer newborn hospitalization, as well as a predisposition toward growth and psychomotor postnatal development deficiencies ${ }^{(16)}$.

The use of birth weight in the evaluation of maternal and child health conditions is highly valued as it can show the quality of life of a community. Historically, low weight was only associated with prematurity, but later studies have showed no significant association, associa- ting other variables to its incidence, such as obstetric factors (intrauterine growth retardation, multiple births), behavioral factors (smoking, drug use), geographic factors (altitudes and regions) and ethnicity. Studies after the 1970s have included non-pathological maternal factors for the occurrence of low birth weight, such as maternal age (less than 20 years or over 35 years) and maternal weight gain during pregnancy (over $8 \mathrm{~kg}$ ). The number of prenatal medical visits is also considered an important factor for the reduction of complications during pregnancy, directly affecting birth weight. In the 1990s, another factor in the occurrence of low birth weight was included: cesarean delivery, which if prescribed indiscriminately could increase the occurrence of preterm deliveries ${ }^{17}$.

Data from this study showed a higher prevalence of overweight newborns (7.20\%) compared to newborns with a low birth weight (6.10\%). This prevalence is higher than that found in the same period in the region of Foz do Rio Itajai Açu (5.87\%) and in the capital city of the state, Florianópolis (5.91\%) ${ }^{(12)}$. The prevalence of overweight at birth (macrosomia) is $5 \%$ of the general population and can increase to $15-25 \%$ in cases of diabetic mothers ${ }^{(18)}$. In Rio de Janeiro, a cohort study conducted from 2005 to 2007 found an incidence of $6.7 \%$ of macrosomia ${ }^{(15)}$; in Goiania, in the period from 2006 to 2008, it reached $6.5 \%{ }^{(19)}$.

Some authors suggest an increasing trend in the number of macrosomic newborns, similar to that of developed countries (UK, 9\%; Germany, 10.1\%; Denmark, 20\%; US, 10\%)(15).

Two cohorts held in Rio de Janeiro in different periods found that macrosomia has as determinants: advanced maternal age, multiparity, pre-pregnancy obesity and excessive weight gain during pregnancy ${ }^{(15)}$.

The spatial analysis of overweight newborns showed a higher risk for the Medeirinhos 
neighborhood, in the countryside. It is a fact that women in this area have a better nutritional condition, from practicing the cultivation of fruits and vegetables in their homes. However, such a nutritional regime should take care to avoid a hypercaloric diet, which increases the chances of excessive weight gain during pregnancy and constitutes a risk factor for macrosomia.

Overweight birth weight is seen as just as important a factor as low birth weight, as this may increase the risk of intrauterine death, fractures, neonatal hyperbilirubinemia, brachial plexus palsy, the need for intensive care, and obesity in childhood and adulthood ${ }^{(19)}$.

The spatial distribution of preterm births in the city of Balneario Piçarras showed a prevalence of prematurity of $6.16 \%$, consistent with that of low birth weight births (6.10\%). The neighborhood with the greatest risk of prematurity was São Braz, which also had the highest risk rate for low birth weight. This percentage was lower than that found in other municipalities, such as Vale do Paraíba, SP (9\%) (6), Niterói, RJ (7.4 to 7.9\%) ${ }^{(5)}$ and Guarapuava, PR $(10 \%)^{(3)}$.

Prematurity, in addition to low birth weight, were the characteristics of newborns that led to the most hospital admissions among children under one year in Maringá, PR, increasing the chance of hospitalization by 2.5 times $^{(20)}$.

A study conducted in Uberlândia, MG, in the years 2008-2010, to analyze the spatial dynamics of the occurrence of low birth weight, prematurity, and the coefficient of infant deaths, found that prematurity is an indicator for low weight at birth and the highest prevalence occurred in neighborhoods that have in common the presence of low-income residents. This indicates that the question of income is still the main cause of a higher incidence of stillbirths in these locations. By using map- ping techniques, it was possible to identify a pattern of occurrence which focused mostly on areas of poor population, with few health services or with management failures in the registration system, suggesting the need for revision in the planning of maternal and child care, which should be considered as a priority of the municipal government ${ }^{(16)}$.

\section{CONCLUSION}

SINASC currently has a coverage area of more than $90 \%$ of Brazil, as seen in several studies around the country, indicating its feasibility for the calculation of health indicators. However, there is still underreporting in the system, detected by information crossing over from other sources, as well as errors in the completion and processing of data.

Despite this, this study allowed us to observe that the spatial analysis showed an increased risk of low birth weight in the rural area of São Braz and the neighborhoods of Bela Vista and Nossa Senhora da Paz, along with elevated risk factors for overweight in Medeirinhos, another rural area, and for prematurity in São Braz. The indicators show that the risks are associated with poor access to health services in rural areas and unfavorable socioeconomic conditions in the neighborhoods of the urban area.

An ongoing evaluation of these health indicators by the government would allow the implementation of strategies for the comprehensive health care of women and children, providing/introducing effective measures to reduce the incidence of infant mortality.

Despite the FHS coverage across 100\% of the area, as well as adequate prenatal coverage, we recommend the implementation of programs to guarantee a quality service, redirecting public policies for the areas most 
deprived of urban infrastructure, to improve the supply of public services, provide adequate care during the prenatal period, tracking and monitoring of risk pregnancies, and to promote actions for the monitoring of the newborns. This set of proposals, guided by georeferencing for risk situations and areas, will enable the improvement of maternal and child indicators in the city.

\section{REFERENCES}

1. Kieviet JF, Piek JP, Aarnoudse-Moens CS, Oosterlaan J. Motor Development in Very Preterm and Very Low-Birth-Weight Children From Birth to Adolescence: A Meta-analysis. JAMA. 2009;302(20):2235-42.

2. Próspero, ENS; Barros, SMO; Goldman, RE. Evolução do peso ao nascer no município de Itajaí, Santa Catarina, Brasil, após a implantação do sistema de informação de nascidos vivos. Saúde Coletiva. 2008;5(21):71-5.

3. Ramos HAC, Cuman RKN. Fatores de risco para prematuridade: pesquisa documental. Esc Anna Nery Rev Enferm. 2009;13(2):297-304.

4. Victora CG, Aquino EM, Leal MC, Monteiro CA, Barros FC, Szwarcwald CL. Saúde de mães e crianças no Brasil: progressos e desafios. Lancet. 2011;377:1863-77.

5. Rozario S, Brito AS, Kale PL, Fonseca SC. Série temporal de características maternas e de nascidos vivos em Niterói, RJ. Rev Bras Saude Mater Infant. 2013;13(2):137-46.

6. Hau LC, Nascimento LFC, Tomazini JE. Geoprocessamento para identificar padrões do perfil de nascimentos na região do Vale do Paraíba. Rev Bras Ginecol Obstet. 2009;31(4):171-76.

7. Barcellos C, Ramalho WM, Gracie, R. et al. Geocoding health data in sub-municipal scale: some Brazilian experiences. Epidemiol Serv Saúde. 2008;17(1):59-70.

8. Monteiro CA, Nazario CL. Evolução de condicionantes ambientais da saúde na infância na cidade de São Paulo (1984 - 1996). Rev Saúde Pública. 2000; 34(6 supl):13-8.

9. Minamisawa R, Barbosa MA, Malagoni L, Andraus LMS. Fatores associados ao baixo peso ao nascer no estado de Goiás. REE. 2006;6(3):336-49.

10. Rodrigues KSF, Zagonel IPS. Perfil epidemiológico de nascimentos em Foz do Iguaçu/PR: indicador para planejamento do cuidado do enfermeiro. Esc Anna Nery Rev Enferm. 2010;14(3):534-42.

11. Guimarães AMDA, Bettiol H, Souza L. et al. Is adolescent pregnancy a risk factor for low birth weight? Rev Saúde Pública. 2013; 47(1):11-9.

12. Departamento de Informática do SUS [home-page in the Internet]. Estatísticas Vitais: Nascidos Vivos [cited 2014 Mai 04]. Available from: http:// www.datasus.gov.br.

13. Viana KJ, Taddei JAAC, Cocetti M, Warkentin S. Peso ao nascer de crianças brasileiras menores de dois anos. Cad Saúde Pública. 2013;29(2):349-56.

14. Silva AAM, Silva LM, Barbieri MA. et al. The epidemiologic paradox low birth weight in Brazil. Rev Saúde Pública. 2010;44(5):767-75.

15. Oliveira RB, Melo ECP, Knupp VMA. Perfil dos óbitos infantis no município do Rio de Janeiro segundo peso ao nascer, no ano de 2002. Esc Anna Nery Rev Enferm. 2008; 13(2):297-304.

16. Vieira AS, Mendes PC. Análise espacial da prematuridade, baixo peso ao nascer e óbitos infantis em Uberlândia-MG. Uberlândia. Hygeia. 2012;8(15):146-56.

17. Silva TRSR. Nonbiological maternal risk factor for low birth weight on Latin America: a systematic review of literature with meta-analysis. Einstein. 2012;10(3):380-85.

18. Tourinho AB, Reis MLBS. Peso ao nascer: uma abordagem nutricional/Birth weight: a nutricional approach. Com Ciên Saúde. 2012;23(1):1930.

19. Costa BMF, Paulinelli RR, Barbosa MA. Association between maternal and fetal weight gain: cohort study. São Paulo Med J. 2012;130(4):24247.

20. Barreto MS, Silva RLDT, Marcon SS. Morbidade em crianças menores de um ano consideradas de risco: estudo prospectivo. Online Braz J Nurs. 2013;12(1):5-18. 
Authors' Contribution

Eneida Patrícia Teixeira Stephan: development and review;

Luciane Peter Grillo: Research consulting and review;

Elisete Navas Sanches Próspero: Research consulting and review;

Rita de Cássia Teixeira Rangel: results discussion and review.
All authors participated in the phases of this publication in one or more of the following steps, in According to the recommendations of the International Committee of Medical Journal Editors (ICMJE, 2013): (a) substantial involvement in the planning or preparation of the manuscript or in the collection, analysis or interpretation of data; (b) preparation of the manuscript or conducting critical revision of intellectual content; (c) approval of the versión submitted of this manuscript. All authors declare for the appropriate purposes that the responsibilities related to all aspects of the manuscript submitted to OBJN are yours. They ensure that issues related to the accuracy or integrity of any part of the article were properly investigated and resolved. Therefore, they exempt the OBJN of any participation whatsoever in any imbroglios concerning the content under consideration. All authors declare that they have no conflict of interest of financial or personal nature concerning this manuscript which may influence the writing and/or interpretation of the findings. This statement has been digitally signed by all authors as recommended by the ICMJE, whose model is available in http://www. objnursing.uff.br/normas/DUDE_eng_13-06-2013.pdf

Received: 08/08/2014

Revised: $12 / 23 / 2014$

Approved: 12/23/2014 